\title{
'||||||||||||||||||||||||||||||||||||||||||||||||||||||||||||||||||.
}

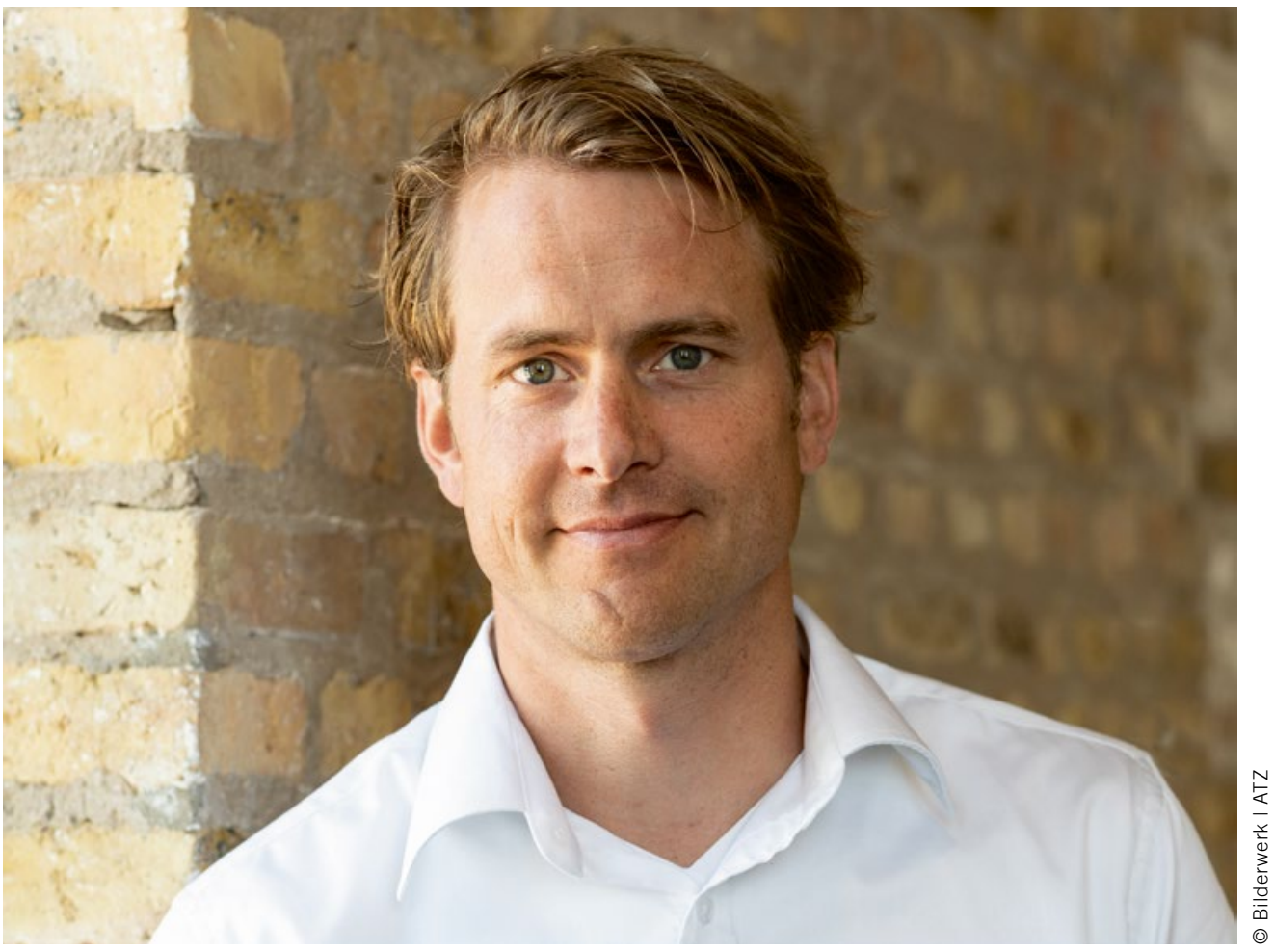

Dipl.-Ing. Jochen Tüting

Managing Director of Chery Europe GmbH, ATZ Advisory Board

\section{Standards as a Driver of Economics}

When my family moved to China in 2013, we decided to take an unfurnished flat to build our own home for the coming years. Looking for European style furniture, we soon found ourselves in-between the high level racks of a Swedish manufacturer. And really, the wardrobe looked the same as in Germany, was built the same and even had the same drawing based manual: one single product for the global market.

What seems completely normal in this context is an exception when it comes to the automotive industry. OEMs and suppliers are being pushed into massive complexity in development and testing by regional regulations. One example: The crash safety standards UN R137, GB 11551-2014 and FMVSS 208 all follow the same purpose - to protect the occupants in case of a frontal crash. However, although tests are quite similar, Europe uses a smaller dummy on the passenger side than China and the USA. And tests in the US are done at $56 \mathrm{~km} / \mathrm{h}$ while China and the EU test at $50 \mathrm{~km} / \mathrm{h}$. The list of even more significant differences would be substantial.

This heterogeneity means a multiplication of efforts on the manufacturers' side in the areas of simulation as well as testing. It might be enough to cover the worst case in some areas, but during homologation at the latest, physical tests are being required. It can be right to take regional differences into account - for example when average body heights are signifi- cantly different across markets. But the fact that smaller dummies are used in Europe on the passenger side in comparison to tests in China shows this currently not being the reason for differentiation.

Globalization is happening - the coronavirus crisis is forcibly making this evident. It is time that the efforts in global harmonization of regulations are picking up speed. The United Nations are following some good initiatives; nevertheless hundreds of millions of euros are getting wasted every year in the automotive industry due to the need to comply with different legal requirements among the regional vehicle markets. Agreeing on global standards would have a lot of winners: the industry due to significantly reduced complexity, governments due to easier type approval processes and finally our customers who could get parts and passenger cars offered at lower prices.

We have one of the biggest automotive standardization processes in decades coming up - the steering wheel will disappear at some point. No left hand drive respectively right hand drive derivatives any more for instrument panel, steering gear or brake lines, etc. The savings will be enormous.

If we are able to think about passenger cars without steering wheels, then I guess global standards on emissions or safety should also be possible. 